\title{
The colour of ochres explained by their composition
}

\author{
M. Elias ${ }^{\mathrm{a}, *}$, C. Chartier ${ }^{\mathrm{a}}$, G. Prévot ${ }^{\mathrm{b}}$, H. Garay ${ }^{\mathrm{c}}$, C. Vignaud $^{\mathrm{d}}$ \\ a Institut des NanoSciences de Paris, UMR 7588 CNRS, Université P. et M. Curie, Campus Boucicaut, 140 rue de Lourmel, 75015 Paris, France \\ ${ }^{\mathrm{b}}$ Ecole Supérieure d'Optique ESO, Centre Scientifique d'Orsay Bat 503, 91403 Orsay Cedex, France \\ ${ }^{\mathrm{c}}$ Ecole des Mines d'Alès, Equipe Propriétés Psychosensorielles des Matériaux, Pau Hélioparc, 2 Avenue P. Angot, 64053 Pau Cedex 09, France \\ ${ }^{\mathrm{d}}$ Laboratoire Interfaces et Systèmes Electrochimiques, UPR 15 CNRS, Université P. et M. Curie, 3 rue Galilée, 94200 Ivry, France
}

\begin{abstract}
The first purpose of this paper is to underline a relevant colorimetric co-ordinate characterizing the colour of ochres within their extremely wide range, from pale yellow to dark red. The second purpose is to link together quantitatively the variations of this colorimetric co-ordinate and the various chemical compositions of the samples, mainly hematite, goethite and white pigments. A group of 30 modern ochres and a group of 20 ancient ochres have been investigated. All these natural pigments have been commercialized. Diffuse reflectance spectrometry allows to calculate the colorimetric co-ordinates in the CIE- $L^{*} a^{*} b^{*}$ space and the position of the absorption band of each sample. Physico-chemical analysis has been obtained by quantitative X-ray diffraction, scanning and transmitting electronic microscopy and particle-size analysis by laser diffraction. The positive $a^{*}$ co-ordinate (redness) has been underlined, for the first time, to be the only relevant colorimetric parameter to characterize the colour of the ochres. Its variations are quantitatively connected to the shift of the absorption band due to the charge transfer between the ligand $\left(\mathrm{OH}^{-}\right.$or $\left.\mathrm{O}^{2-}\right)$ and the $\mathrm{Fe}^{3+}$ ion contained in goethite and/or hematite. For ochres containing both hematite and goethite, the $a^{*}$ co-ordinate linearly increases with the relative amount of hematite while the absorption band progressively shifts towards the high wavelengths. Such a linear shift of the absorption band has never been underlined before. For ochres containing only one iron oxide, $a^{*}$ linearly decreases with the amount of white pigments, whatever the nature of the white charges. Moreover, this study gives the opportunity to show that only the nature, the amount and the size distribution of the white charges allow to discriminate the ochres according to their geographic origin.
\end{abstract}

Keywords: Ochre; Hematite; Goethite; Colorimetry; Reflectance spectroscopy; Scanning electron microscopy; Transmission electron microscopy; X-ray diffraction; Particle size; Charge transfer

\section{Introduction}

The great interest of ochres is based on the extremely wide range of their colours. Actually, it spreads from yellow to orange, to red and to violet. The principal purpose of this paper is to link together quantitatively the colour of ochres and their chemical composition with the aim of explaining such a large colour variation. To achieve it, a relevant colorimetric co-ordinate must be underlined.

Natural ochres [1,2] were used from Antiquity - the oldest site with ochre deposits 380,000 years old - in the artistic and craft fields for wall paintings, body paintings and funeral rituals. They have been transformed into commercially acceptable pigments from the 19th century to produce a bright palette of

\footnotetext{
* Corresponding author.

E-mail address: elias@ physique.univ-evry.fr (M. Elias).
}

colour, extremely stable, non-fading, non-bending, with a strong tinting strength and reproducible shades. They are used in the construction, coating and paint industries and are among the few pigments approved by the American Society for Testing and Materials (ASTM). In spite of the development of the synthetic pigment industry, natural industrial ochres supply today $20 \%$ of world consumption. For this reason, the present study focuses on commercial ochres coming from the main supplying countries. We will not call upon their geological composition, because all ores have been washed and heated, thus modifying the original goethite contained in the ore.

Ochres contain varying amounts of octahedral iron oxides, namely hematite $\left(\alpha \mathrm{Fe}_{2} \mathrm{O}_{3}\right)$ or/and goethite $(\alpha \mathrm{FeOOH})$, and of white pigments (alumino-silicate as kaolinite or illite, quartz and calcium compounds as calcite, anhydrite, gypse or dolomite). When the hematite is the main iron oxide, a red colour is observed, whereas the ochre is yellow when the goethite dominates. These colours are due to the ion $\mathrm{Fe}^{3+}$ contained in both 
oxides and more precisely to the charge transfer between $\mathrm{Fe}^{3+}$ and its ligands $\mathrm{O}^{2-}$ or $\mathrm{OH}^{-}$. The current literature on iron oxides rarely links together spectro-colorimetric and physico-chemical analysis [2-5] and until now, never in a quantitative way. Nevertheless, structural studies of ochres are numerous, mostly applied to pure goethite, pure hematite and to the dehydration of goethite to hematite, especially in prehistoric paintings. They call upon various techniques like Mössbauer effect [6,7], thermal analysis [8], FT-IR spectroscopy [9-12], X-ray diffraction [4,8-11,13-15], Raman microscopy [12,15] and magnetic and voltamperemetric analyses [16]. Seven experimental techniques are used in this study. Spectro-photo-colorimetry is implemented to record the diffuse reflectance spectra in a back-scattering configuration and to calculate the trichromatic co-ordinates in the CIE 1964- $L^{*} a^{*} b^{*}$ space. The structural composition is obtained by quantitative X-ray diffraction (XRD), using Rietveld refinement. The morphology of the compounds is imaged by scanning electron microscopy (SEM) coupled to an energy dispersive spectroscopy (EDS) and by transmission electron microscopy (TEM). Finally, granularity by laser diffraction is implemented in order to quantify the size of the aggregates present in the ochres, and thus to check if the previous spectra can be compared.

This study will also give an opportunity to look for the relevant parameters distinguishing ochres according to their geographic origin.

\section{Experimental}

\subsection{Sample description}

Twenty-nine industrial ochres in powder are investigated. All of them have been washed, grinded and sometimes heated. Fourteen samples come from Vaucluse (numbering ending in V), in the south of France, where the quarries were opened in 1785 (Société des Ocres de France and Lamy society located in Apt). Six samples come from Puisaye (Bourgogne) (numbering ending in $\mathrm{P}$ ), in the center of France, where the quarries were open between 1763 and 1966 (Quieffin society). Six samples come from Italy (Dolci society) (numbering ending in I), two from Madras (India) (numbering ending in $\mathrm{M}$ ) and one from Sweden (numbering ending in S). Another group of 20 old industrial ochres, more than 100 years old, coming from Vaucluse, was also studied by spectro-colorimetry.

\subsection{Experimental methods}

The experiments are separated in three sub-sections leading to colour, structural composition and morphology.

\subsubsection{Spectro-photo-colorimetry}

2.2.1.1. Diffuse reflectance spectrum. The diffuse reflectance spectrum is an optical label of the sample only if the bulk light scattering is collected without any surface effect. With this purpose, a rigorous protocol is implemented. Before recording the spectrum, it is checked that the surface of each sample is perfectly orthotropic (Lambertian) using gonio-photometry and changing the back-scattering angle. Moreover, it is checked that the light reflected from the bottom of the sample holder is negligible. The device is an optical fibers gonio-spectro-photocolorimeter with a special back-scattering configuration [17]. A back-scattering angle always equal to $22^{\circ}$ is used to record the spectra in the visible range, in order that the light reflected by the rough upper surface is also minimized. The device allows a 3-nm wavelength resolution and a precision on the reflectance factor equal to $0.1 \%$.

2.2.1.2. Colorimetry. The trichromatic co-ordinates of the colour are then computed from the measured reflectance spectrum. These co-ordinates take into account the spectral density of the illuminant $S(\lambda)$, the three relative sensibility curves of the standard observer $\bar{x}(\lambda), \bar{y}(\lambda)$ and $\bar{z}(\lambda)$ and the diffuse reflectance spectrum of the sample $R(\lambda)$. Here, the illuminant D65, which simulates the daylight, and the standard observer defined by the CIE-1964 are chosen. The calculation of the $X, Y$ and $Z$ trichromatic components is first implemented, according to:

$$
\begin{aligned}
X & =K \cdot \int S(\lambda) \cdot \bar{x}(\lambda) \cdot R(\lambda) \mathrm{d} \lambda \\
Y & =K \cdot \int S(\lambda) \cdot \bar{y}(\lambda) \cdot R(\lambda) \mathrm{d} \lambda \\
Z & =K \cdot \int S(\lambda) \cdot \bar{z}(\lambda) \cdot R(\lambda) \mathrm{d} \lambda \\
K & =\frac{100}{\int S(\lambda) \cdot \bar{y}(\lambda) \mathrm{d} \lambda}
\end{aligned}
$$

Then, the $L^{*} a^{*} b^{*}$ space, defined by the CIE-1976, which is more uniform than the $X, Y, Z$ space, is chosen, and the new co-ordinates are deduced from the formers: the achromatic lightness $L^{*}$ and two chromatic components $a^{*}$ (green-red axis) and $b^{*}$ (blue-yellow axis). Each co-ordinate is calculated from the measured reflectance spectrum with a 0.1 unit precision.

\subsubsection{Composition by quantitative $X$-ray diffraction}

$X$-ray diffraction measurements are performed on a Siemens D5000 diffractometer using the Co K $\alpha$ radiation $(\lambda=1.789 \AA$, $40 \mathrm{kV}, 40 \mathrm{~mA})$, a parallel beam $(0.6 \mathrm{~mm} \times 12 \mathrm{~mm})$ and Göbel's mirrors. The EVA code is used for the identification of the peaks. Quantitative analysis is obtained by the Rietveld refinement using the TOPAS code. Beforehand, different calibrated mixtures of hematite (or goethite) and calcite have been analysed to check the validity of the quantitative results. These calibrations lead to a standard deviation equal to $1 \%$ for the proportion of each compound.

\subsubsection{Morphology}

2.2.3.1. Scanning electron microscopy. Scanning electron microscopy coupled with energy dispersive spectroscopy is implemented to get the size and the shape of the different compounds and to confirm the XRD results. Back-scattered electron (BSE) images and elementary analysis by EDS are carried out on a JEOL JSM-840 microscope equipped with a $\mathrm{Si}(\mathrm{Li}) \mathrm{X}$-ray 
detector. The secondary electrons are used to get images and the spatial resolution is about $1 \mu \mathrm{m}$.

\subsubsection{Transmission electron microscopy. TEM observations} are conducted using a $200 \mathrm{kV}$ JEOL to get information on the microstructure of the compounds and their crystallized state. The pigment powder is ground in an agate mortar and then dispersed in ethanol. A drop of this preparation is deposited on a special carbon covered copper grid. After evaporation, thin monocrystals (transparent to the $200 \mathrm{kV}$ electron beam) are lying on the carbon film and then observed and identified by electron diffraction.

2.2.3.3. Grain size analysis by laser diffraction. The particle size distribution of the different ochres is determined by laser diffraction on a Coulter LS230 apparatus. The samples are wetted out before measurement. Several measurements are carried out on the same sample in order to evaluate the state of agglomeration. The presented results correspond to the state of the smallest agglomeration.

\section{Results}

\subsection{Diffuse reflectance spectra}

These spectra are presented in Fig. 1 and separated in three groups: the red ochres (Fig. 1a), the yellow ochres (Fig. 1b) and the orange ochres (Fig. 1c). The diffuse reflectance spectra of pure hematite and pure goethite, obtained with the same setup are, respectively, inserted in Fig. 1a and b. The spectra of the ochres present the characteristic features, respectively, of the hematite and of the goethite, especially the sharp positive slope at wavelengths higher than $600 \mathrm{~nm}$ for the hematite and red ochres, and lower than $600 \mathrm{~nm}$ for the goethite and the yellow ochres. Red and yellow ochres spectra, like hematite and goethite spectra, also differ by a strong maximum around $730 \mathrm{~nm}$ in the first case and a secondary minimum about $660 \mathrm{~nm}$ in the second case. The spectra of the orange ochres presented in Fig. 1c show features halfway between the spectra of hematite and goethite.

In order to differentiate the ochres, it is necessary to characterize the wavelength range of the sharp slope. In this purpose, the wavelength of the inflexion point $\lambda_{\mathrm{m}}$ is considered because it is easily obtained as the abscissa of the maximum of the first derivate of each spectrum. From the measured spectra, $\lambda_{m}$ is evaluated to $550 \mathrm{~nm}$ for pure goethite and to $580 \mathrm{~nm}$ for pure hematite. For the yellow ochres, $\lambda_{\mathrm{m}}$ varies between 535 and $565 \mathrm{~nm}$. For the orange ochres, $\lambda_{\mathrm{m}}$ varies between 565 and $580 \mathrm{~nm}$. For the red ochres, $\lambda_{\mathrm{m}}$ lies between 575 and $580 \mathrm{~nm}$. The different values of $\lambda_{\mathrm{m}}$ are summarized in the last column of Table 1 for all the modern ochres. It is the first time, to our knowledge, that such a continuous evolution of $\lambda_{\mathrm{m}}$ in similar samples has been underlined.

\subsection{Colorimetric co-ordinates}

The colorimetric $L^{*} a^{*} b^{*}$ co-ordinates are given in Table 1 for all the modern ochres. They are presented in three dimensions in Fig. $2 \mathrm{a}$ and $\mathrm{b}$, for two rotations around the $L^{*}$ axis and with
Table 1

Trichromatic co-ordinates $L^{*} a^{*} b^{*}$ and wavelength $\lambda_{\mathrm{m}}$ associated to the sharp slope of the spectrum for the modern ochres

\begin{tabular}{|c|c|c|c|c|}
\hline No. & $L^{*}$ & $a^{*}$ & $b^{*}$ & $\lambda_{\mathrm{m}}(\mathrm{nm})$ \\
\hline $15 \mathrm{I}$ & 61.8 & 6.5 & 49.6 & 534 \\
\hline $16 \mathrm{I}$ & 62.8 & 19.5 & 54.5 & 571 \\
\hline $17 \mathrm{I}$ & 50.1 & 34.1 & 46.9 & 581 \\
\hline $18 \mathrm{I}$ & 51.6 & 43.3 & 68.1 & 582 \\
\hline 19I & 48.1 & 35.9 & 62.0 & 579 \\
\hline $21 \mathrm{I}$ & 80.2 & 8.9 & 66.2 & 541 \\
\hline $25 \mathrm{~V}$ & 77.7 & 11.1 & 60.5 & 548 \\
\hline $26 \mathrm{~V}$ & 76.5 & 10.6 & 65.2 & 537 \\
\hline $27 \mathrm{~V}$ & 75.7 & 12.0 & 61.8 & 550 \\
\hline $28 \mathrm{~V}$ & 66.8 & 17.3 & 53.8 & 564 \\
\hline $29 \mathrm{~V}$ & 61.4 & 23.6 & 57.1 & 572 \\
\hline $30 \mathrm{~V}$ & 54.4 & 29.4 & 57.4 & 565 \\
\hline $31 \mathrm{~V}$ & 50.0 & 32.3 & 62.4 & 577 \\
\hline $32 \mathrm{~V}$ & 54.3 & 34.4 & 60.0 & 576 \\
\hline $45 \mathrm{~V}$ & 69.8 & 17.9 & 55.5 & 565 \\
\hline $33 \mathrm{M}$ & 39.8 & 32.0 & 53.2 & 580 \\
\hline $34 \mathrm{M}$ & 61.7 & 9.8 & 53.6 & 547 \\
\hline $36 \mathrm{P}$ & 71.3 & 12.4 & 61.6 & \\
\hline $37 \mathrm{P}$ & 55.3 & 26.4 & 58.1 & 575 \\
\hline $38 \mathrm{P}$ & 49.1 & 34.8 & 58.0 & 581 \\
\hline 39P & 49.5 & 21.9 & 47.4 & 581 \\
\hline $43 \mathrm{P}$ & 72.2 & 12.6 & 62.0 & 545 \\
\hline $44 \mathrm{P}$ & 48.0 & 33.9 & 53.2 & 579 \\
\hline $42 \mathrm{~S}$ & 46.5 & 30.0 & 49.6 & 581 \\
\hline
\end{tabular}

the same units on each axis. The $a^{*}$ co-ordinate (green-red axis) stands between 4.4 and 43.3 with a relative variation of $163 \%$. The $b^{*}$ co-ordinate (blue-yellow axis) stands between 37.7 and 68.1 with a smaller relative variation of $57.5 \%$. The lightness $L^{*}$ varies by $73.4 \%$. The same observations have been made for 15 ochres coming from Vaucluse and manufactured during the 19th century. By comparing both chromatic co-ordinates, $a^{*}$ varies 2.8 times more than $b^{*}$ for modern ochres and 4.2 times more than $b^{*}$ for older ochres. For differentiating the ochres by a colorimetric parameter, the $a^{*}$ co-ordinate appears more discriminatory and thus more relevant than $b^{*}$. The positive values of $a^{*}$ correspond to the redness which was already qualitatively reported as a characteristic of the ochres [3] in the Munsell system. This property is here certainly emphasized with use of the $L^{*} a^{*} b^{*}$ space.

The colorimetric results are thus projected in the $\left(L^{*}, a^{*}\right)$ plane in Fig. 3 for modern and old ochres. For both groups, smaller the $a^{*}$ co-ordinate, greater the lightness $L^{*}$, the variation being approximately linear. This result must be tied to the influence of the relative amount of white pigments contained in the ochres. Fig. 3 also points out that the nature of the white pigments does not influence the relationship between lightness and redness: ochres from different origins and then with different compositions have been gathered in this graph. Finally, Fig. 3 also shows that aging does not affect this colorimetric result: ochres from 20th and 19th centuries present the same colorimetric behaviour.

Moreover, no specific relationship between the $b^{*}$ co-ordinate and the lightness $L^{*}$ has been pointed out, confirming the choice 

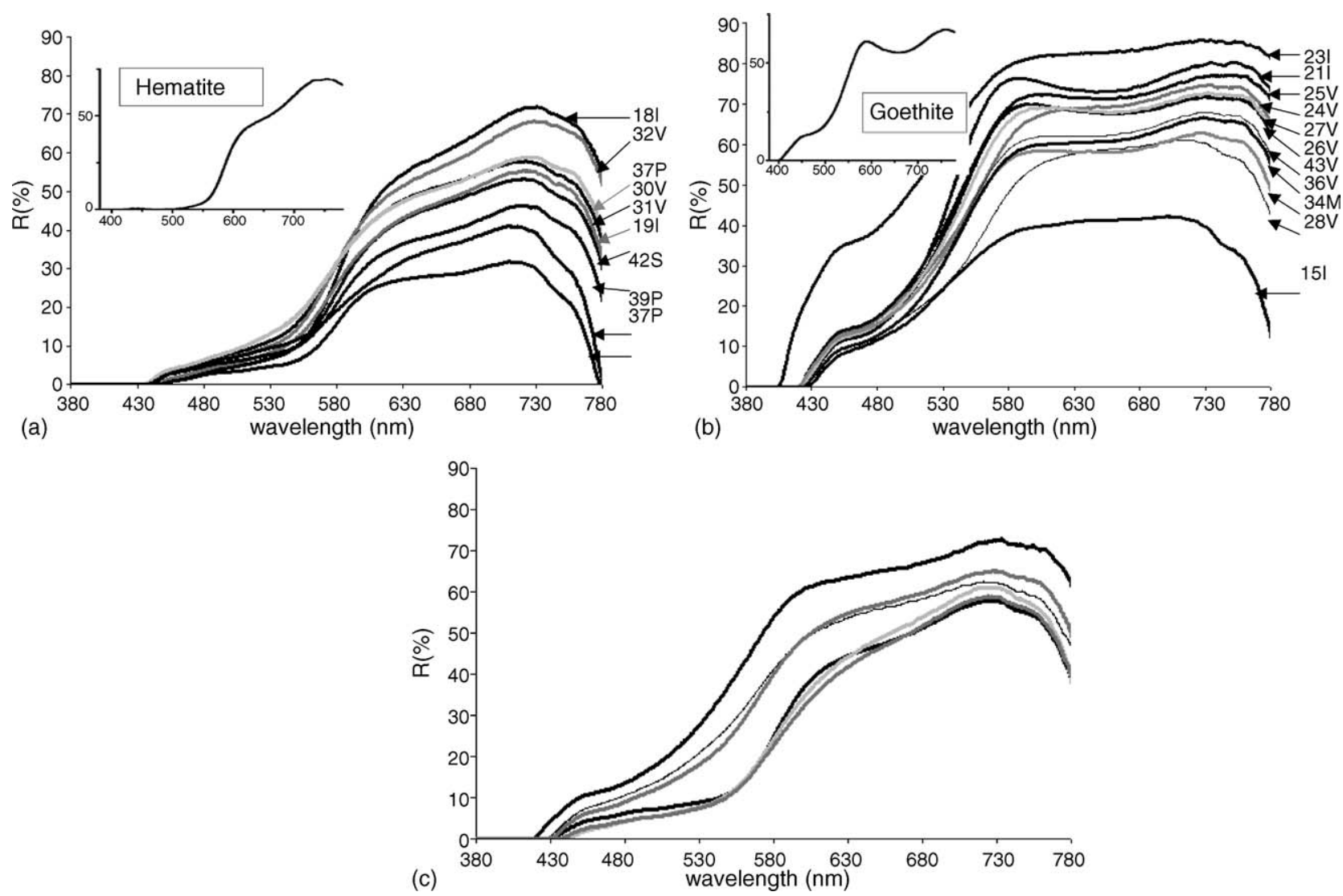

Fig. 1. Diffuse reflectance spectra of: (a) red ochres, (b) yellow ochres and (c) orange ochres.

of the $a^{*}$ co-ordinate to quantitatively characterize the colour of ochres.

Consequently, the co-ordinate $a^{*}$ will be chosen from now as the only relevant colorimetric co-ordinate of the ochres.

\subsection{Composition of the ochres by quantitative XRD}

The quantitative molar composition of the samples is given in Table 2. The diffractogram obtained for the ochre no. 32V is presented in Fig. 4, as an example. The phases identification with the EVA code is shown in Fig. 4a; their quantitative molar composition obtained with the modeling of Rietveld refinement are shown in Fig. 4b.

All the ochres contain iron oxides. The red ochres with spectra gathered in Fig. 1a have a molar concentration in hematite higher than $80 \%$ compared to the total iron oxides and their $a^{*}$ co-ordinate varies between 24.6 and 43 . All the yellow ochres with spectra gathered in Fig. 1b only contain goethite and no

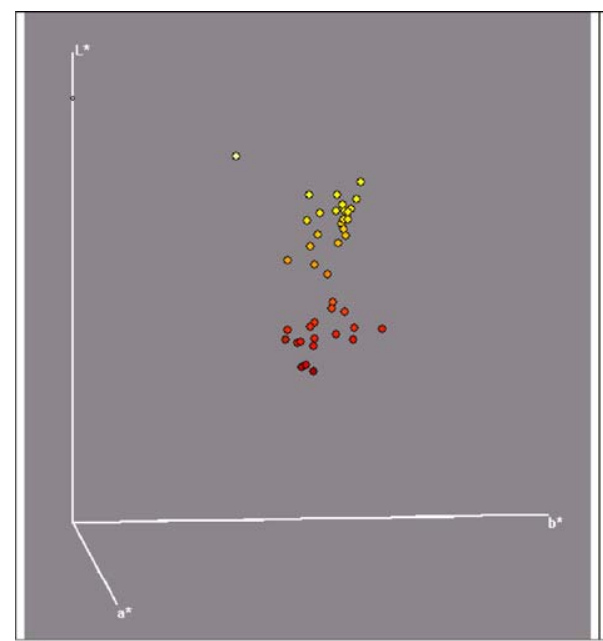

(a)

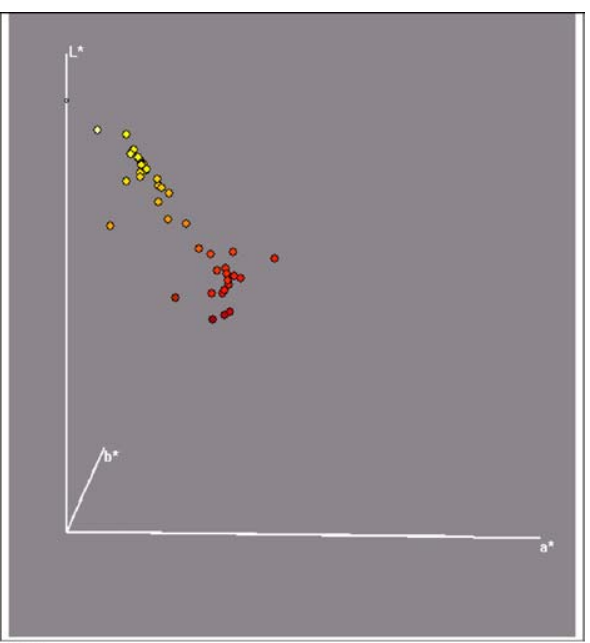

(b)

Fig. 2. (a and b) Colorimetric co-ordinates of ochres in the $L^{*} a^{*} b^{*}$ space. 
Table 2

Molar concentration (\%) of the different compounds contained in the modern ochres

\begin{tabular}{|c|c|c|c|c|c|c|c|c|c|}
\hline No. & Goethite & Hematite & Kaolinite & Quartz & Illite & Calcite & Anhydrite & Gypse & Dolomite \\
\hline $15 \mathrm{I}$ & 12.98 & 0 & 3.22 & 3.56 & 22.05 & 58.20 & 0 & 0 & 0 \\
\hline $16 \mathrm{I}$ & 29.51 & 9.89 & 19.52 & 0.77 & 0.04 & 32.39 & 0 & 6.57 & 1.31 \\
\hline 17I & 1.17 & 8.28 & 0.01 & 0.26 & 1.09 & 0.03 & 0 & 89.18 & 0 \\
\hline $18 \mathrm{I}$ & 1.78 & 9.70 & 0 & 0.46 & 0.11 & 0 & 0 & 87.93 & 0.07 \\
\hline 19I & 0.18 & 22.32 & 16.58 & 0.12 & 5.17 & 3.57 & 0 & 52.08 & 0 \\
\hline $21 \mathrm{I}$ & 12.11 & 0 & 0.05 & & 0.05 & 11.72 & 0 & 75.75 & 0 \\
\hline $23 \mathrm{~V}$ & 3.00 & 0 & 25.45 & 70.12 & 1.43 & 0 & 0 & 0 & 0 \\
\hline $24 \mathrm{~V}$ & 28.38 & 0 & 26.75 & 41.77 & 0.64 & 2.48 & 0 & 0 & 0 \\
\hline $25 \mathrm{~V}$ & 23.17 & 0 & 24.30 & 37.91 & 0.38 & 14.24 & 0 & 0 & 0 \\
\hline $26 \mathrm{~V}$ & 28.21 & 0 & 12.30 & 15.57 & 1.90 & 42.01 & 0 & 0 & 0 \\
\hline $27 \mathrm{~V}$ & 36.07 & 0 & 23.78 & 38.07 & 1.35 & 0.73 & 0 & 0 & 0 \\
\hline $28 \mathrm{~V}$ & 25.38 & 0 & 21.11 & 33.89 & 4.06 & 15.58 & 0 & 0 & 0 \\
\hline $29 \mathrm{~V}$ & 29.97 & 13.00 & 21.37 & 32.02 & 0.72 & 2.93 & 0 & 0 & 0 \\
\hline $30 \mathrm{~V}$ & 0 & 30.19 & 26.34 & 37.90 & 1.53 & 4.01 & 0 & 0 & 0 \\
\hline $31 \mathrm{~V}$ & 0 & 30.52 & 26.45 & 37.97 & 1.10 & 4.00 & 0 & 0 & 0 \\
\hline $32 \mathrm{~V}$ & 0 & 30.87 & 7.00 & 55.87 & 3.52 & 2.70 & 0 & 0 & 0 \\
\hline $33 \mathrm{M}$ & 0.18 & 99.10 & 0.56 & 0.27 & 0 & 0 & 0 & 0 & 0 \\
\hline $34 \mathrm{M}$ & 65.01 & 0 & 22.52 & 0 & 0.67 & 11.86 & 0 & 0 & 0 \\
\hline $37 \mathrm{P}$ & 25.50 & 10.34 & 7.52 & 52.07 & 4.59 & 0 & 0 & 0 & 0 \\
\hline $38 \mathrm{P}$ & 2.10 & 24.54 & 3.06 & 64.50 & 5.60 & 0.22 & 0 & 0 & 0 \\
\hline $39 P$ & 9.20 & 37.04 & 10.10 & 40.59 & 3.06 & 0 & 0 & 0 & 0 \\
\hline $42 \mathrm{~S}$ & 0.13 & 36.38 & 0 & 49.57 & 1.08 & 4.43 & 8.41 & 0 & 0 \\
\hline
\end{tabular}

hematite and their $a^{*}$ co-ordinate varies between 4.4 and 17.3. The orange ochres with spectra gathered in Fig. 1c contain a mixture of hematite and goethite and their $a^{*}$ co-ordinate varies between 19.5 and 34.8. Hematite and goethite are the iron oxide, respectively, responsible for the red and yellow colours. Moreover, the ranges of variation of the $a^{*}$ co-ordinate are markedly separated for the three previous groups of ochres. These results are independent of the geographic origin of the ochres. So, it is clearly underlined that a quantitative relationship must exist between $a^{*}$ and the concentration of iron oxides.

The nature and the concentration of the white pigments allow to distinguish the ochres according to their origin. All the ochres contain hydrated alumino silicate: kaolinite $\mathrm{Al}_{2} \mathrm{Si}_{2} \mathrm{O}_{5}(\mathrm{OH})$ and illite $\left(\mathrm{K}, \mathrm{H}_{3} \mathrm{O}\right)(\mathrm{Al})_{2}(\mathrm{Si}, \mathrm{Al})_{4} \mathrm{O}_{10}\left[(\mathrm{OH})_{2}, \mathrm{H}_{2} \mathrm{O}\right]$. Both minerals are very often associated in all red earth because illite is easily converted in kaolinite in acid and waterlogged soils. But ochres

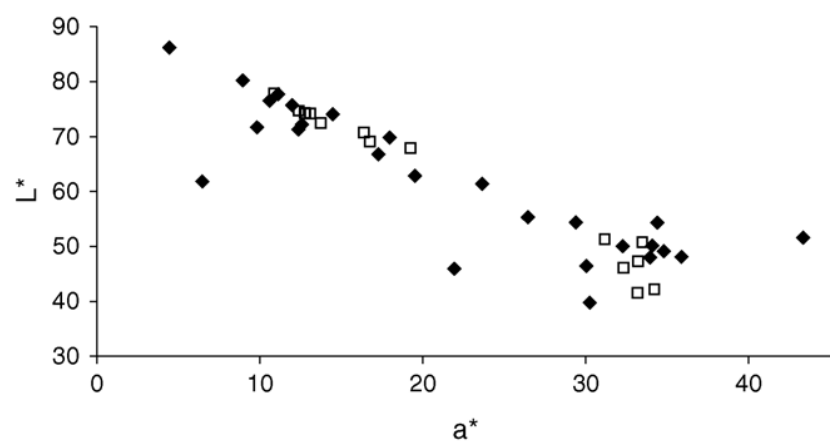

Fig. 3. Variation of the lightness $L^{*}$ as a function of the $a^{*}$ co-ordinate for modern and ancient ochres - white squares for ochres of 19th century and black diamond for modern ochres. coming from Vaucluse are clearly distinguishable from others by their high concentration of kaolinite, around $20 \%$. Ochres from Puysaye contain more illite and less kaolinite than those from Vaucluse. Calcium compounds are present in all ochres as calcite $\mathrm{CaCO}_{3}$ almost every time, as gypsum $\mathrm{CaSO}_{4} \cdot 2 \mathrm{H}_{2} \mathrm{O}$ in Italian ochres, as anhydrite $\mathrm{CaSO}_{4}$ in the Sweden ochre $42 \mathrm{~S}$ and as dolomite $\mathrm{CaMg}\left(\mathrm{CO}_{3}\right)_{2}$ in some Italian ochres. The origin of these compounds, especially calcite, is probably due to the washing treatment of the commercial ochres. Finally, quartz $\mathrm{SiO}_{2}$ is a common component of all ochres, more present in the ochres coming from Vaucluse.

\subsection{Morphology}

Even if the colour of a material is mainly due to the nature of its compounds (here iron oxides and white pigments), it is modulated by the size of the agglomerates of the scattering centers. So, the later comparison of the colours of different samples according to their composition will be valid only if these sizes are similar. It is the reason why electron microscopy is implemented at different scales. The study is improved by laser diffraction to get the size distribution of all the agglomerates.

\subsubsection{SEM-EDS}

A cartography of the ochre no. $32 \mathrm{~V}$, as a back-scattered electron image, is presented in Fig. 5. The greyscale contrast is function of the $Z$ atomic number variations. From white to dark grey, the corresponding elements are identified by energy X-ray spectroscopy (EDS) as ${ }_{26} \mathrm{Fe}$, then ${ }_{20} \mathrm{Ca},{ }_{14} \mathrm{Si}$ and ${ }_{13} \mathrm{Al}$. The presence of hematite, calcite, quartz, kaolinite and illite is in good agreement with the XRD results of Table 2 . 

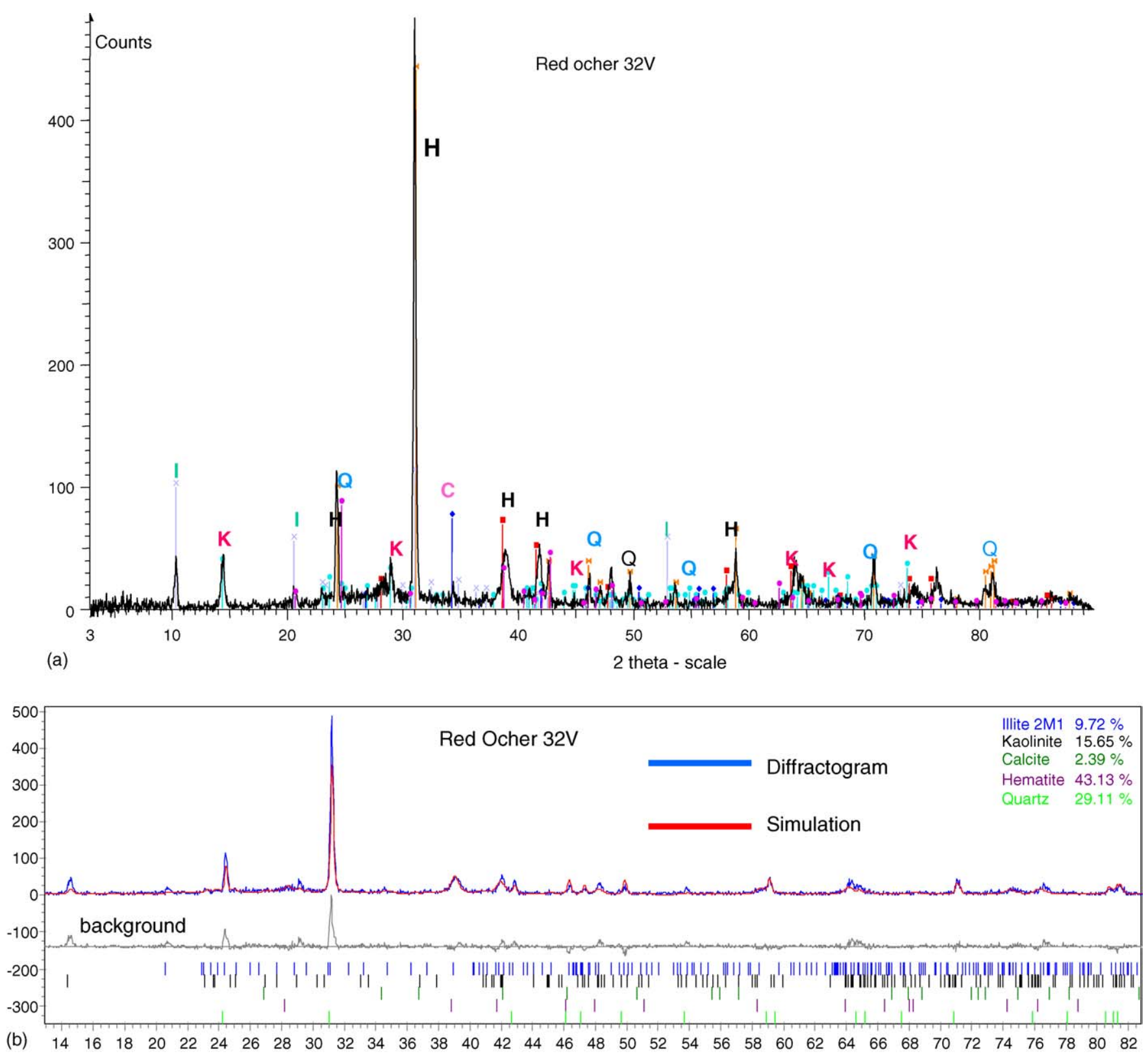

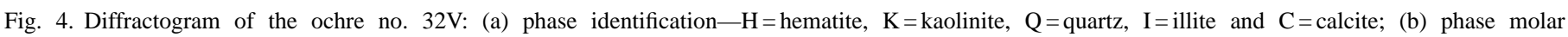
composition-30.87\% hematite, $7.00 \%$ kaolinite, $55.87 \%$ quartz, $3.52 \%$ illite and $2.70 \%$ calcite.

Moreover, the size of these compounds can be roughly estimated and stand around a few micrometers, except quartz, that is around $50 \mu \mathrm{m}$.

\subsubsection{TEM}

Three micrographs of the ochre $31 \mathrm{~V}$ obtained by TEM are presented in Fig. 6a-c. Crystal size and information are collected about the hematite origin in the studied industrial ochre [14]. In Fig. $6 \mathrm{a}$, it is possible to recognize the characteristic feature of acicular goethite. A more accurate observation allows to identify nanopores inside the acicular crystal. These pores are the sign of a nearly complete transformation by dehydration heat treatment (near $400{ }^{\circ} \mathrm{C}$ ) of goethite into hematite. Yet external shape of this crystal is still the acicular shape of the original goethite but the crystallographic structure of this crystal is the hematite one. In Fig. 6b, on the upper right half side of the crystal, we registered the beginning of the in situ dehydration phenomenon under the electron beam. It appears as longitudinal channels which correspond to the early stage before pores formation. It means that before the induced electron beam damage, this crystal was goethite. In the same carbon grid preparation, a third type of crystals is present in Fig. 6c. This hexagonal shape is characteristic of the hematite structure after the recrystallization process above $800^{\circ} \mathrm{C}$.

These three families (goethite, dehydrated goethite and recrystallized hematite) are present in the same sample. It underlines the strongly heterogeneous temperature of the heat process undergone by this industrial ochre pigment. 


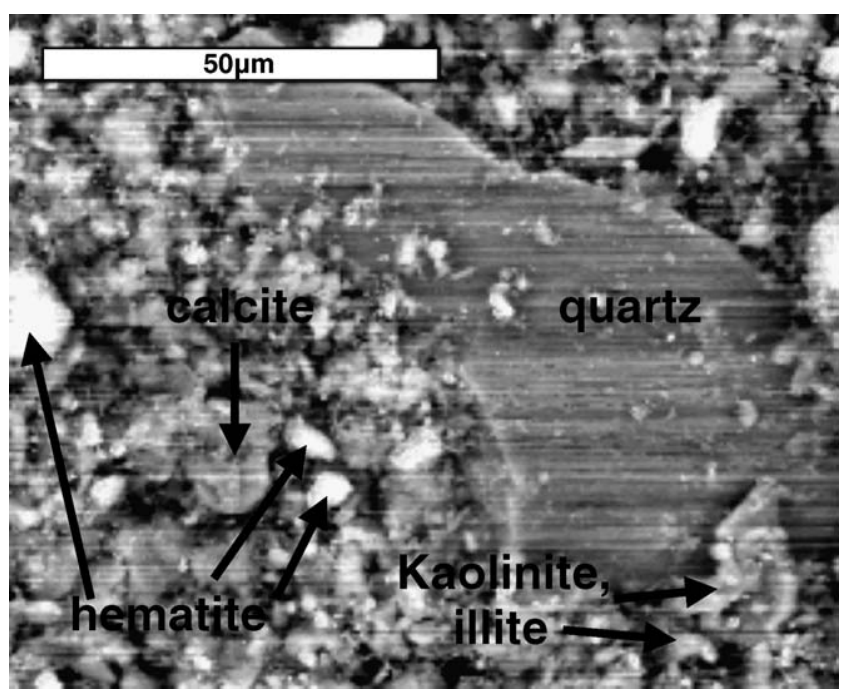

Fig. 5. Cartography of the ochre no. 32V, obtained by SEM in BSE mode coupled to EDS.

\subsubsection{Laser diffraction}

Laser diffraction was implemented to get the size distribution of the agglomerates contained in the studied samples. This information is necessary to check that the size of the scatterers, in a given set of ochres, is similar and larger than the wavelength in the visible range, so that light scattering obeys Mie theory. The spectra and the colorimetric co-ordinates of different ochres can then be compared, according only to their composition and not to their size. Measurements show a multimodal distribution of the sizes for each sample. The distributions are quite spread (from less than $1 \mu \mathrm{m}$ to more than $100 \mu \mathrm{m}$ ) and are in accordance with the SEM images. By comparison with the composition obtained from XRD, it is obvious that ochres presenting similar chemical composition show similarities in their particle size distribution too. For example, Fig. 7a shows the granulometry of the three ochres coming from Puisaye. The curves present peaks at the same particle size and the curve slopes are similar. Fig. 7b shows the diversity of the curves obtained according to their geographic origin and thus to their different composition. The identification of the peaks is performed by comparison with the different compositions of the samples: a special peak for gypse in Italian ochres that only contain this compound and a special peak for quartz common to French ochres. White pigments generally present very large and intense bands peaking at 5-10 $\mu \mathrm{m}$ size distributions but remain indistinguishable. Iron oxides present typical peaks around 30 and $50 \mu \mathrm{m}$ and a small one near $1 \mu \mathrm{m}$, whatever their origin. These peaks have been previously identified from pure samples containing only goethite or hematite. For colour explanation, it can be deduced that the light scattered by the pigments is incoherent and follows Mie theory because the size of the pigments is always larger than the wavelength in the visible range. Moreover, the size of the iron oxides agglomerates around 40 and $0.8 \mu \mathrm{m}$ does not depend on the origin of the ochres and thus the spectra and colorimetric co-ordinates of the ochres can be compared by taking into account only their composition.

\section{Discussion}

\subsection{Colour investigation}

\subsubsection{Interpretation of the diffuse reflectance spectra}

The colour of pure goethite and pure hematite is mainly explained by the ligand-to-metal charge transfer (CT) transition: the $6 \mathrm{t}_{1 \mathrm{u}}\left(\mathrm{O}^{2-}\right.$ or $\left.\mathrm{OH}^{-}\right) \rightarrow 2 \mathrm{t}_{2 \mathrm{~g}}\left(\mathrm{Fe}^{3+}\right)$. This transition leads to a strong light absorption peaking in the UV range and extending to the visible range. In the diffuse reflectance spectra, it induces a minimum of reflectance in the UV range and a strong positive slope corresponding to the absorption edge in the visible range. The same strong absorption band is present in the diffuse reflectance spectra of all the ochres (Fig. 1a-c). The wavelength $\lambda_{\mathrm{m}}$ corresponding to the inflexion point of the absorption edge allows to quantify the position of the CT band (last column of Table 1). $\lambda_{\mathrm{m}}$ continuously varies between 535 and $580 \mathrm{~nm}$ according to the composition of the ochres and thus to their colour.

A second specificity of pure hematite and goethite is the spin and parity forbidden $\mathrm{d}-\mathrm{d}$ transitions $[2,18]$. The $\mathrm{Fe}^{3+}$ ion presents the $\mathrm{d}^{6}$ configuration in an octahedral symmetry generated by the $\mathrm{O}^{2-}$ and $\mathrm{OH}^{-}$ligands. The ${ }^{6} \mathrm{~A}_{1 \mathrm{~g}} \rightarrow{ }^{4} \mathrm{~T}_{2 \mathrm{~g}}$ transition induces weak absorption bands at $649 \mathrm{~nm}$. The pair transition $2\left({ }^{6} \mathrm{~A}_{1 \mathrm{~g}}\right) \rightarrow 2\left({ }^{4} \mathrm{~T}_{1 \mathrm{~g}}\right)$ appears at $480 \mathrm{~nm}$ for goethite and $529 \mathrm{~nm}$ for hematite. Another ${ }^{6} \mathrm{~A}_{1 \mathrm{~g}} \rightarrow{ }^{4} \mathrm{~A}_{1 \mathrm{~g}},{ }^{4} \mathrm{E}_{\mathrm{g}}$ transition exists at $434 \mathrm{~nm}$ for goethite and $444 \mathrm{~nm}$ for hematite. These d-d transition bands are present in the spectra of all the ochres. The relative variation of their intensity is less than $0.1 \%$ (the precision of the reflectance factor) and does not seem to be influenced by the various compositions of the samples and cannot explain the corresponding colour changes. Actually, the CT transitions are not bound by strict selection rules, as $\mathrm{d}-\mathrm{d}$ transitions, and their absorption coefficient is around $10^{5}$ times larger than for a d- $\mathrm{d}$ transition. Moreover, the more ionic the bond between $\mathrm{Fe}^{3+}$ and the ligands, i.e. the more electronegative the ligand, the more shift of the CT band towards small wavelengths. This explains that $\lambda_{m}$ and the position of the $\mathrm{CT}$ band change with the composition of the ochres and are the main reason of the colour variations.

\subsubsection{Colour and diffuse reflectance spectra}

Fig. 8 connects the relevant colorimetric co-ordinate $a^{*}$ to the relevant position of the absorption edge $\lambda_{\mathrm{m}}$ for all the studied ochres, modern and ancient. The $a^{*}$ co-ordinate increases logically with increasing $\lambda_{\mathrm{m}}$ : the shift of the CT absorption edge towards high wavelengths means that the ochre absorbs less radiations in the red range. No specific relationship exists between the $b^{*}$ co-ordinate and $\lambda_{\mathrm{m}}$. These results show that the colour of the ochres is mainly influenced by the position of CT absorption edge and that $\lambda_{\mathrm{m}}$ is a relevant parameter to link the spectra and the colour of the ochres, in this case their redness. This shift induces progressive colour changes from pale yellow to dark red. It is the first time that such a quasi-linear shift of the position of the absorption band with the redness has been pointed out. It encourages us to envisage, in a near future, a theoretical study with an ab initio model of electron transport 


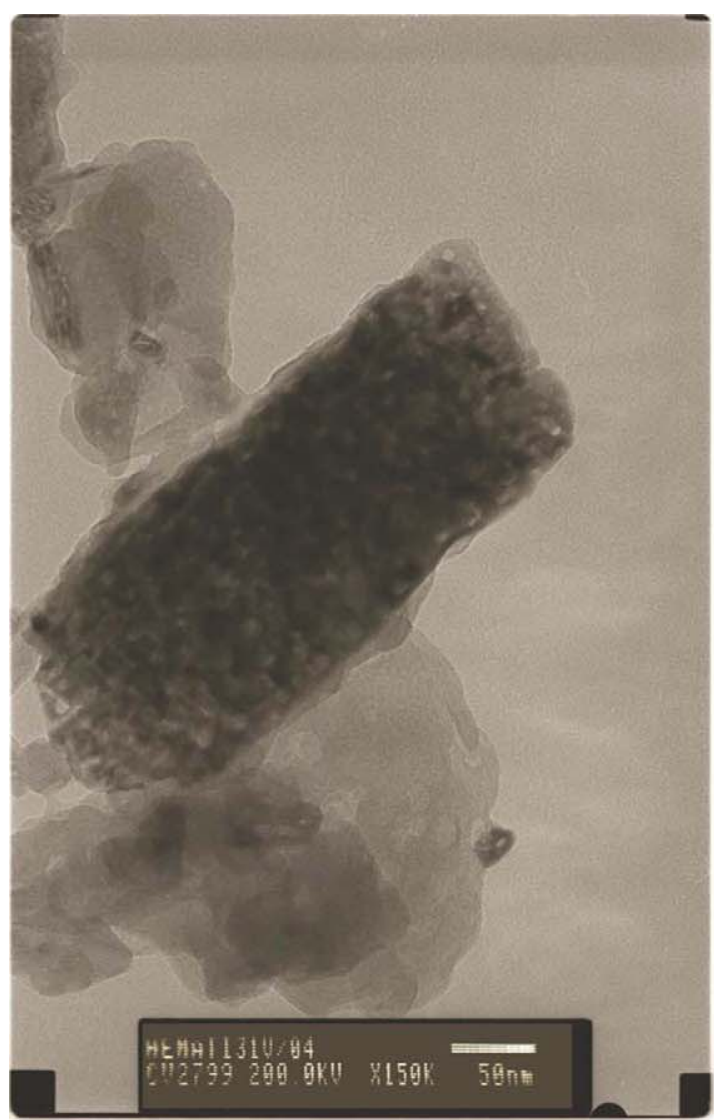

(a)

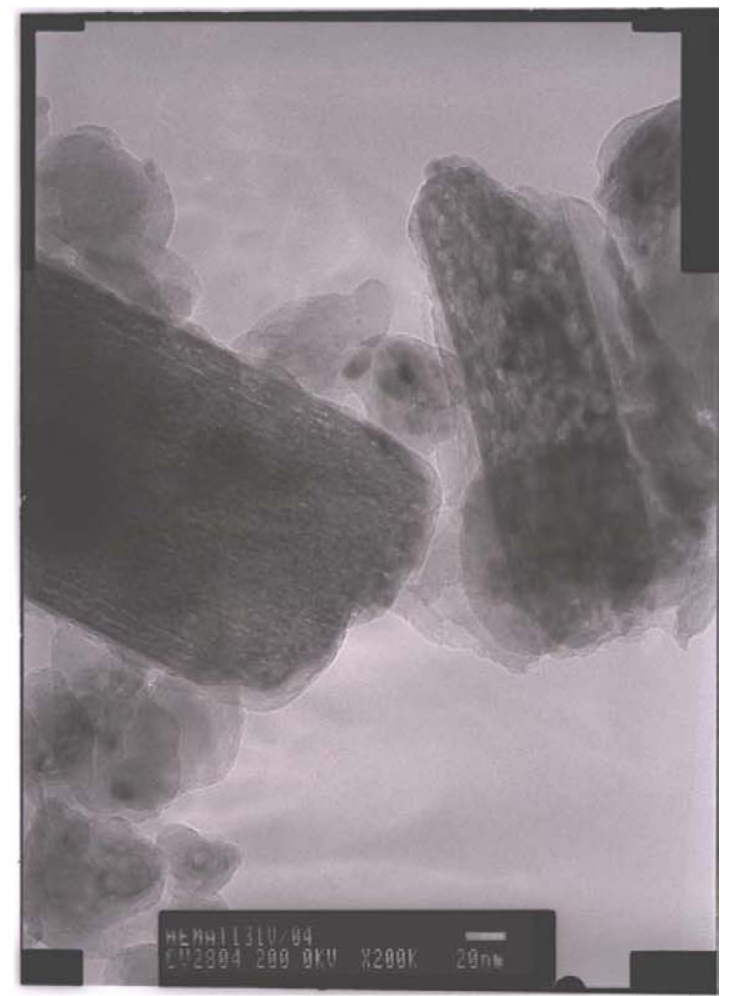

(b)

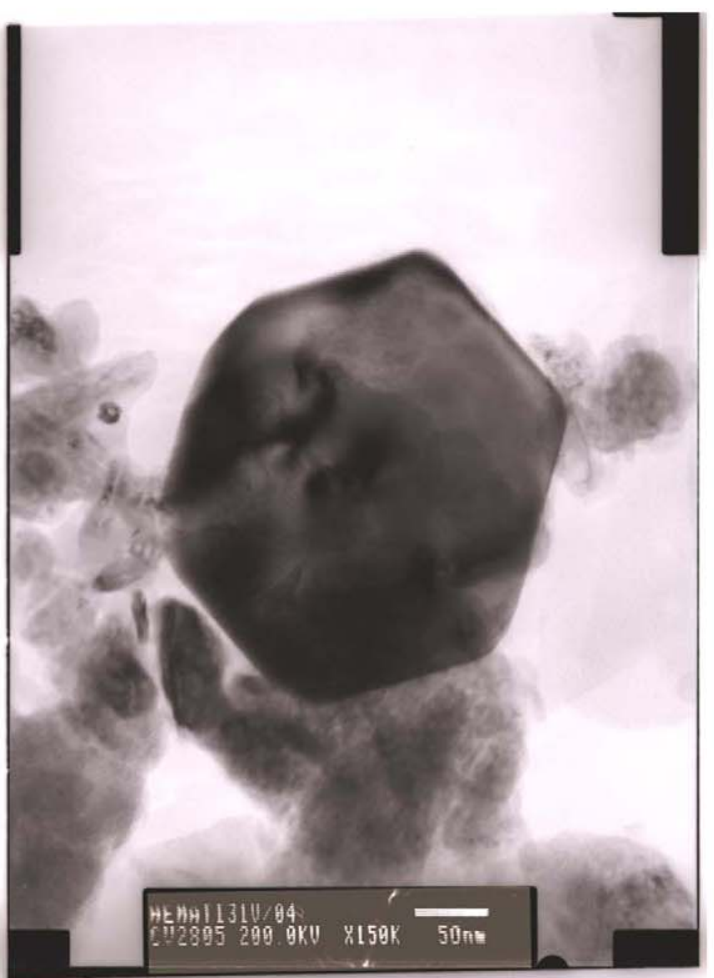

(c)

Fig. 6. (a-c) Cartographies of the ochre no. 31V, obtained by TEM. 

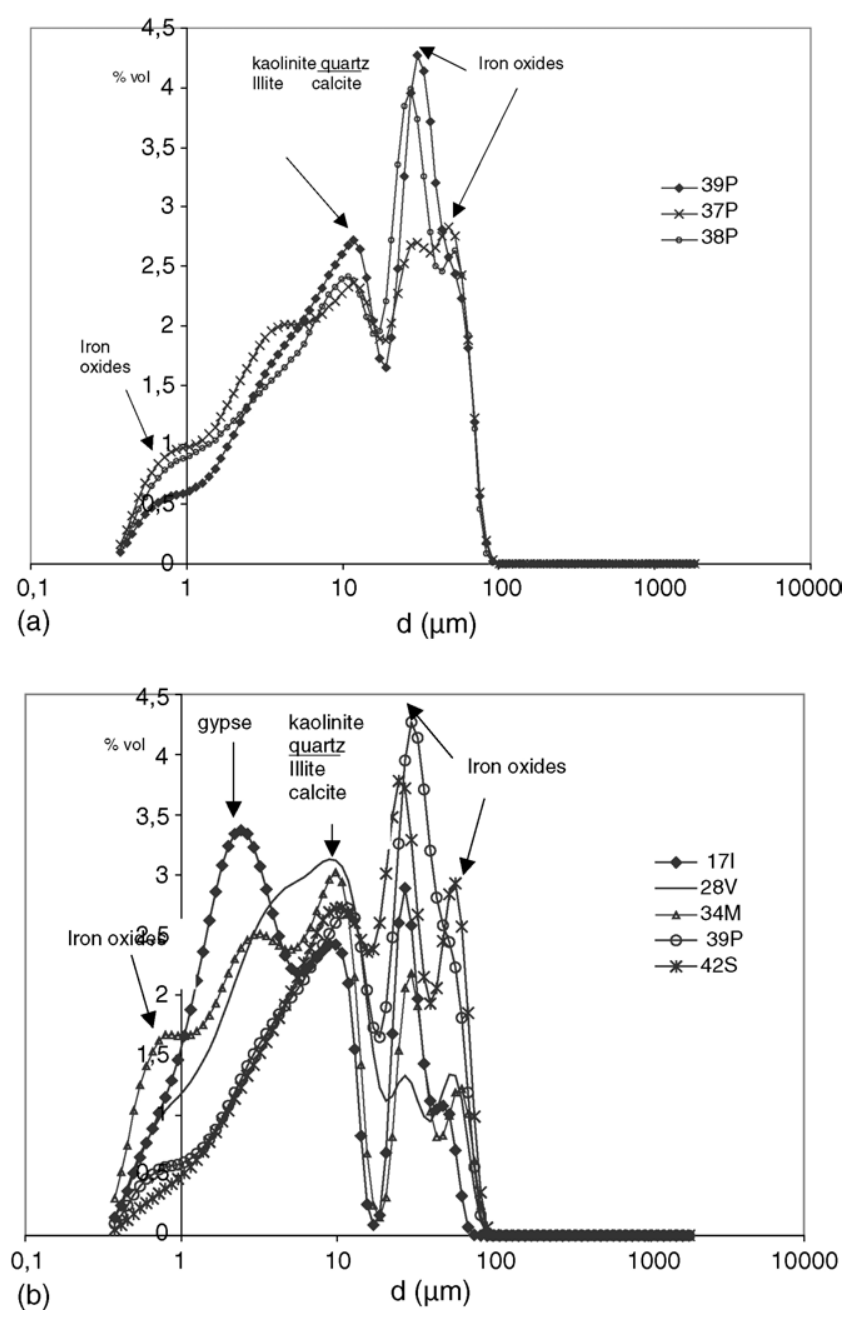

Fig. 7. Size distribution by laser diffraction for: (a) three ochres coming from Puysaye and (b) ochres from Italy, Vaucluse, India (Madras), Puysaye and Sweden.

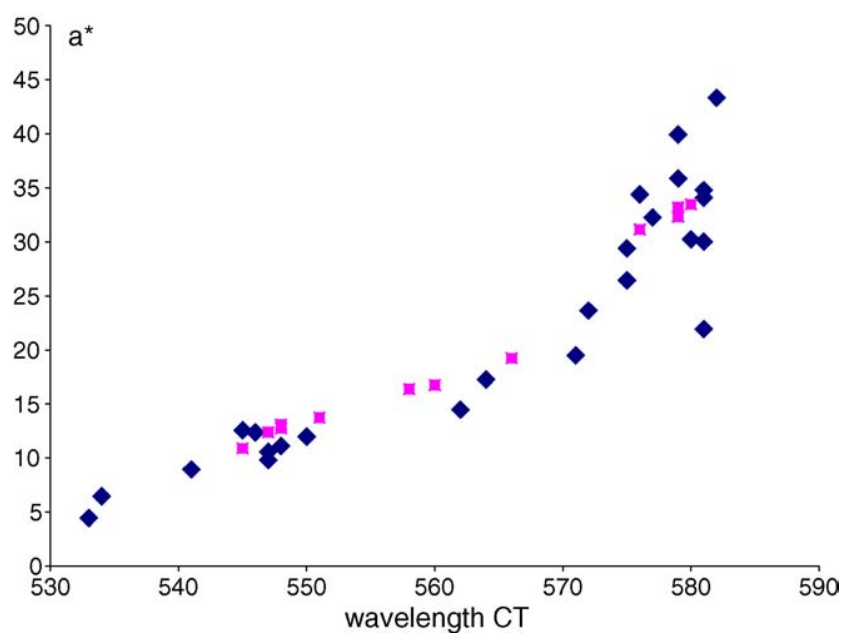

Fig. 8. $a^{*}$ co-ordinate as a function of the wavelength $\lambda_{\mathrm{m}}$ of the absorption edge for modern ochres (squares) and ancient ochres (diamond).

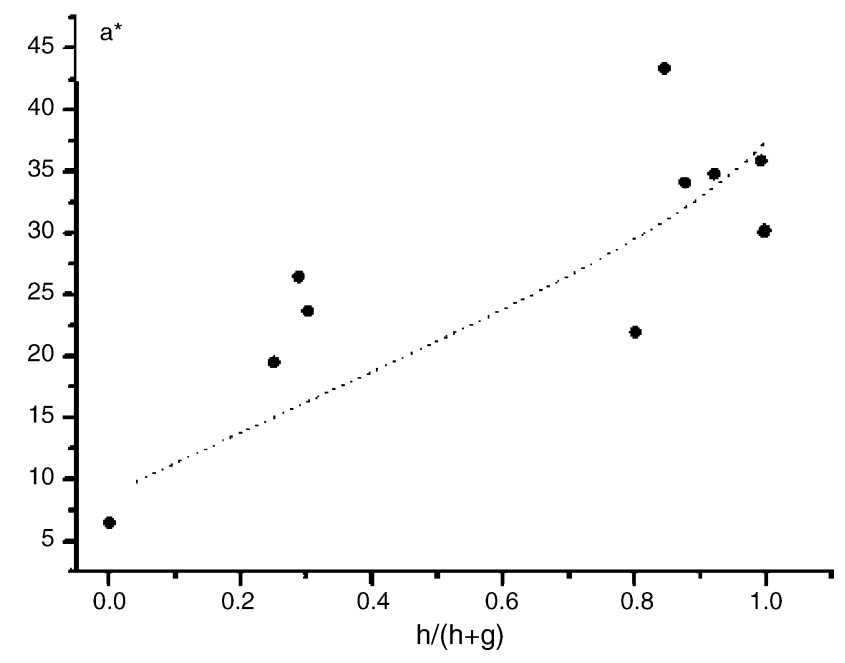

Fig. 9. $a^{*}$ co-ordinate as a function of the molar ratio hematite/(goethite + hematite) for orange modern ochres.

to calculate this shift, as it was already done for hematite [19-21].

\subsubsection{Colour and relative amount of iron oxides}

The ochres consisting mainly of goethite $(15 \mathrm{I}, 21 \mathrm{~V}-28 \mathrm{~V}$, $34 \mathrm{M})$ are characterized by a small value of $a^{*}$ (smaller than 17), whereas those containing mostly hematite (17I, 19I, 30V-32V, $33 \mathrm{M}, 38 \mathrm{P}, 42 \mathrm{~S}$ ) exhibit a high value of $a^{*}$ (larger than 30). The former ones are logically yellow, whereas the latter ones are red.

For ochres containing a mixture of hematite $(\mathrm{h})$ and goethite $(\mathrm{g}), a^{*}$ varies between 20 and 35 and stands in the orange range. Simultaneously, $\lambda_{\mathrm{m}}$ varies between 565 and $580 \mathrm{~nm}$. The wavelength $\lambda_{\mathrm{m}}$ increases with the increase of hematite in the total molar amount of iron oxides, namely the ratio $h /(h+g)$. The increasing quantity of hematite in ochre shifts the $\mathrm{CT}$ absorption band towards higher wavelengths, so $a^{*}$ increases with the ratio $\mathrm{h} /(\mathrm{h}+\mathrm{g})$ as shown in Fig. 9. This qualitatively obvious result is here quantitatively underlined for the first time and will be used to validate later ab initio calculations. Moreover, no such progressive shift of the colour and of the absorption band with the ratio of one constituent has been previously underlined in the literature.

\subsubsection{Colour and relative amount of white pigments}

The colour variation can be connected to the relative proportion of goethite and hematite for the ochres containing both iron oxides. However, for ochres containing only one iron oxide, the colorimetric co-ordinates and the characteristic wavelength $\lambda_{\mathrm{m}}$ of the TC band also vary with the global composition of the samples. These variations are linked to the various amounts of white pigments, such as kaolinite, quartz, illite, calcite, gypsum and dolomite. The diffuse reflectance spectrum of each of these white charges is quasi-wavelength-independent in the visible range [22]. Thus, the colour variation is independent of the nature of the white pigments, as is already pointed out from Fig. 3.

Nevertheless, the relative amount of these charges affects the colour of the ochres containing only one iron oxide. Table 3 
Table 3

Total relative variation of the redness $a^{*}$, of the lightness $L^{*}$ and of the wavelength $\lambda_{\mathrm{m}}$ of the absorption band for ochres containing only goethite or hematite

\begin{tabular}{llll}
\hline Iron oxide & $\Delta \lambda_{\mathrm{m}} / \lambda_{\mathrm{m}}$ & $\Delta a^{*} / a^{*}$ & $\Delta L^{*} / L^{*}$ \\
\hline Goethite & 5.5 & 75 & 32.6 \\
Hematite & 0.9 & 15.8 & 29.4 \\
\hline
\end{tabular}

summarizes the relative variations of $\lambda_{\mathrm{m}}, a^{*}$ and $L^{*}$ for ochres containing from 60 to $100 \%$ of white pigments and only goethite or hematite. It is obvious that goethite is more sensitive to its surroundings than hematite.

For the ochres containing goethite, the increase in white pigment content induces a shift of the CT band towards the small wavelengths, an obvious decrease of the $a^{*}$ co-ordinate, as shown in Fig. 10, an expected increase of the lightness $L^{*}$, an increase of the reflectance factor and a flatness of the spectrum. The pigments become lighter and yellower and these colour changes are consistent with the dilution of a coloured pigment in white pigments. The extreme example corresponds to the pale yellow ochre $23 \mathrm{~V}$, with $97 \%$ of white pigments, the highest lightness $L^{*}=86$, the weakest value of $a^{*}=4.4$ and a flat spectrum with the highest reflectance factor.

For hematite-based ochres, the dilution with white pigments affects much less the position of the CT band and thus the colour of the samples: only the increase of the lightness with white charges content is significant. Two extreme examples correspond to the dark red ochre $33 \mathrm{M}$, with less than $1 \%$ of white charges and the smallest lightness $L^{*}=39.8$, and the rather light red ochre $32 \mathrm{~V}$ with $69 \%$ of white charges and a higher lightness $L^{*}=54.3$. Both red ochres have rather similar values of $a^{*}$ and $\lambda_{\mathrm{m}}$.

The nature of the white charges does not influence the colour of ochres containing only one iron oxide. The colour of goethite is more sensitive to its dilution with white charges than hematite. Once more, these obvious qualitative results have here been quantified thanks to both relevant parameters $a^{*}$ and $\lambda_{\mathrm{m}}$.

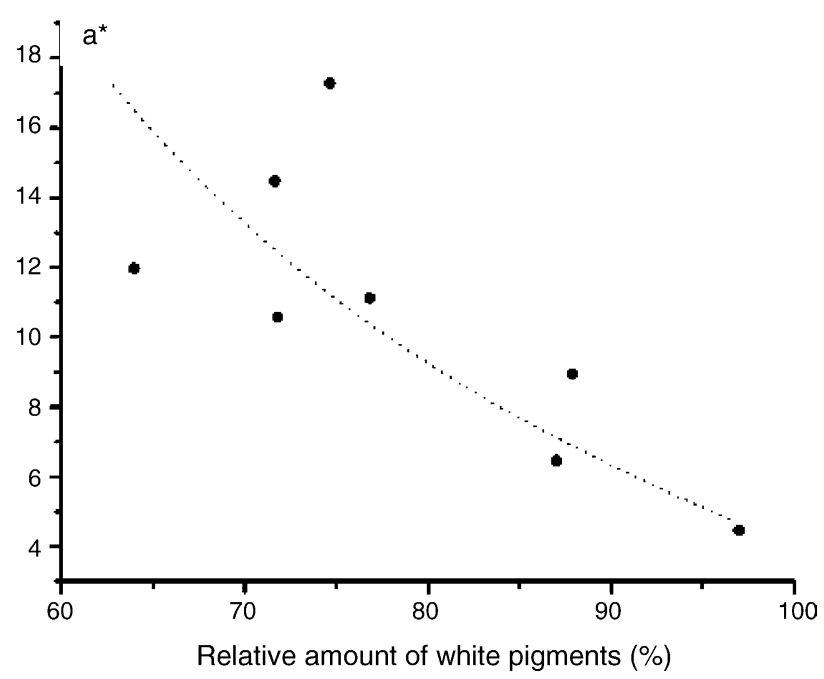

Fig. 10. $a^{*}$ co-ordinate as a function of amount of white pigments for yellow modern ochres.

\subsection{Ochre-differentiation according to their origin}

The large number of data obtained in this experimental study is also an opportunity to differentiate the ochres according to their geographic origin, although it is not the first aim of the study. The colour of an ochre does not depend of its origin, as shown before from Fig. 3 by example. Only the nature, the quantity and the size distribution of the white pigments contained in the ochre can allow to go back to their geographic location.

The ochres coming from Italy are the only one that contain gypsum and sometimes dolomite, among the studied samples. They contain a very small amount of quartz (less than $4 \%$ ) and of kaolinite (less than 20\%). The main sizes of the corresponding agglomerates are around 2.5 and $10 \mu \mathrm{m}$.

The large amounts of kaolinite (between 3 and 27\%) and much more of quartz (between 15 and 70\%) characterize the ochres coming from France (Vaucluse and Puisaye). The absence of calcite in the ochres coming from Puisaye enables to distinguish them from those coming from Vaucluse. The main sizes of the white agglomerates are around 12 and $30 \mu \mathrm{m}$ for ochres coming from Puisaye and around 7 and $57 \mu \mathrm{m}$ for those coming from Vaucluse.

The only ochre from Sweden does not contain kaolinite but anhydrite. Both Indian ochres coming from Madras contain a low quantity of quartz, as Italian ochres but no gypsum. But these last results cannot be generalized before studying more samples.

Quantitative XRD and laser diffraction appear to be the appropriate analyses to assume this discrimination.

\section{Conclusion}

This experimental study of 30 modern industrial ochres and 20 old ones underlines for the first time a relevant and single colorimetric co-ordinate to quantify and to characterize the colour of the ochres. This $a^{*}$ co-ordinate is deduced from the diffuse reflectance spectrum and expressed in the CIE- $L^{*} a^{*} b^{*}$ space. Ochres contain various amounts of goethite and/or hematite where the light induces a charge transfer between $\mathrm{O}^{2-}$ or $\mathrm{OH}^{-}$ and $\mathrm{Fe}^{3+}$ and an absorption band, here characterized by the wavelength of the inflexion point in the diffuse reflectance spectrum of the sample. A quantitative linear relationship has been found between this wavelength and the colorimetric co-ordinate $a^{*}$.

For ochres containing both goethite and hematite, the absorption band moves continuously towards high wavelengths when the amount of hematite in the total molar amount of iron oxides increases, so $a^{*}$ increases. Such a quantified quasi-linear shift, mentioned for the first time, is independent of the nature of the white charges and of the age of the ochres. It will be theoretically modeled, in a near future, using ab initio calculations, as it has been already done for pure hematite.

For ochres containing only one iron oxide, the colorimetric co-ordinate $a^{*}$ progressively decreases with the relative amount of white pigments and the relationship does not depend on the nature of the white charges. The effect is more pronounced for goethite than for hematite. The increase of the white pigment amount then leads to a shift of the absorption band towards the 
small wavelengths and induces a lighter and yellower colour. Ab initio calculations will be once more implemented to explain the phenomenon.

The large amount of data on the structural composition of the samples was also an opportunity to differentiate the ochres according to their geographic origin. Only the nature, the amount and the agglomerate size of the white pigments, obtained by XRD or laser diffraction, were found to be characteristic of the geographic provenance of the pigments.

\section{Acknowledgement}

The authors thank the Conservatoire des Ocres et Pigments Appliqués OKHRA in Roussillon-Provence, France, for the supply of samples.

\section{References}

[1] L. Zuppiroli, M.-N. Bussac, Traité des Couleurs, Presses Polytechniques et Universitaires Romandes, Lausanne, 2001.

[2] R.M. Cornell, U. Schwertmann, The Iron Oxides, second ed., Wiley/VCH, Weinheim, 2003.

[3] J. Torrent, V. Barron, Clays Clay Mater. 51 (3) (2003) 309-317.

[4] S. Watana, I. Kheoruenromne, A. Suddhiprakarn, R.J. Gilkes, 17th Symposium WCSS, Thailand, 2002, p. 2150-1.

[5] T. Nagano, S. Nakashima, S. Nakayama, M. Senoo, Clays Miner. Soc. 42 (1994) 226-234.
[6] A.K. Singh, B.K. Jain, K. Chandra, J. Phys. D: Appl. Phys. 11 (1978) $55-61$.

[7] U. Casellato, P.A. Vigato, U. Russo, M. Matteini, J. Cult. Heritage 1 (2000) 217-232.

[8] C. Genestar Julia, C. Pons Bonafé, Thermochim. Acta 413 (2004) 185-192.

[9] H.D. Ruan, R.L. Frost, J.T. Kloprogge, L. Duong, Spectrochim. Acta Part A 58 (2002) 479-491.

[10] H.D. Ruan, R.L. Frost, J.T. Kloprogge, Spectrochim. Acta Part A 57 (2001) 2575-2586.

[11] G.A. Mazzocchin, F. Agnoli, S. Mazzocchin, I. Colpo, Talanta 61 (2003) 565-571.

[12] D. Bikiaris, Sister Daniilia, S. Sotiropoulou, O. Katsimbiti, E. Pavlidou, A.P. Moutsatsou, Y. Chryssoulakis, Spectrochim. Acta Part A 56 (1999) 3-18.

[13] M.P. Pomiès, G. Morin, C. Vignaud, Eur. J. Solid State Inorg. Chem. 35 (1998) 9-25.

[14] M.P. Pomiès, M. Menu, C. Vignaud, J. Eur. Ceram. Soc. 19 (1999) $1605-1614$

[15] R. Clark, M. Lucia Curri, J. Mol. Struct. 440 (1998) 105.

[16] T. Grygar, J. Dedecek, P.P. Kruiver, M.J. Dekkers, P. Bezdicka, O. Schneeweiss, Catena 53 (2003) 115.

[17] G. Dupuis, M. Elias, L. Simonot, Appl. Spectrosc. 56 (10) (2002) 1329-1336.

[18] D.M. Sherman, T.D. Waite, Am. Mineral. 70 (1985) 1262.

[19] M. Catti, V. Valerio, R. Dovesi, Phys. Rev. 51 (12) (1995) 7441-7450.

[20] L.M. Sandratskii, J. Kübler, Europhys. Lett. 33 (6) (1996) 447-452.

[21] K.M. Rosso, D.M.A. Smith, M. Dupuis, J. Chem. Phys. 118 (14) (2003) 6455-6466.

[22] http://speclab.cr.usg.gov/spectral.lib04.html. 